\title{
Cury, M. X. (org.). (2020). Museus Etnográficos e Indigenas: aprofundando questões, reformulando ações. São Paulo: Secretaria de Cultura e Economia Criativa/ ACAM Portinari/ Museu de Arqueologia e Etnologia da Universidade de São Paulo/ Museus Índia Vanuíre. 248 p.
}

\author{
RONALDO DE OLIVEIRA CORREA
}

UNIVERSIDADE FEDERAL DO PARANÁ (UFPR), CURITIBA/PR, BRASIL

HTTPS://ORCID.ORG/OOOO-0003-I894-I944

O livro organizado por Marília Xavier Cury, museóloga e educadora de museus, professora do Programa de Pós-Graduação Interunidades em Museologia (PPGMus-USP), vinculada ao Museu de Arqueologia e Etnologia da Universidade de São Paulo (MAE-USP), tem caráter híbrido, como o caracteriza, em seu livro Culturas Hibridas (tradução publicada pela Edusp em 2000), Néstor García Canclini, antropólogo argentino radicado no México. Aqui, retomo o questionamento formulado por García Canclini a respeito das disputas em contextos interculturais e sobre o que não se hibridiza. Dito de outra forma, o autor propõe buscar e interpretar quais dimensões políticas, simbólicas e práticas em disputa não entram em consenso nas arenas interculturais contemporâneas. Com essa lente, entendo ser profícua a leitura do livro lançado em 2020, a partir de material produzido no marco do Encontro Paulista de Questões Indígenas e Museus (EPQIM), em sua edição de 2017.

Ao apresentar-se como livro, registro, documento, implicam-se na sua fatura - e logo, leitura os conflitos interculturais presentes na relação apresentada em seu título, a saber, museus etnográficos e indígenas, assim como aqueles presentes na(s) tipologia(s) acionada(s) (livro, registro, documento, outro). Tal relação, ou melhor seria dizer, tais relações, promovem e acolhem, por um lado, articulações políticas e simbólicas entre grupos indígenas de diferentes etnias - Kaingang, Krenak, Terena e Guaraní Nhandewa -, habitantes das terras indígenas (T.I.) na região Centro-Oeste do estado de São Paulo, em relação a suas percepções e perspectivas a respeito de suas experiências, constituição e políticas da vida e memória e, por outro, estabelecem diálogo entre esses grupos e instituições não indígenas, em especial o Museu Índia Vanuíre (MIV), a Associação Cultural de Apoio ao Museu Casa de Portinari (ACAM Portinari), o Museu de Arqueologia e Etnologia da Universidade de São Paulo (MAE-USP) e a Secretaria de Cultura e Economia Criativa do Estado de São Paulo, pautado pelas discussões sobre as políticas públicas de patrimônio e cultura. 
Ainda sobre as intencionalidades presentes no título do livro e sua potência para marcar os conteúdos apresentados, o subtítulo nos provoca a refletir, com autoras e autores, a respeito do caráter temporal e processual da relação proposta no título. Isso é denunciado na informação de ser a edição de 2017, a sexta edição de um total de sete, realizadas no período de 2012 a 2018, pelo MIV, como parte das táticas para a constituição de práticas e políticas museológicas marcadas pela postura crítica e pelo acolhimento dos indígenas nos processos de gestão, pesquisa e difusão do museu, além da proposição de ações vinculadas às vivências desses sujeitos que permitam descolonizar o cotidiano da instituição. Tal posicionamento pautado pela Constituição Brasileira de 1988 - a constituição cidadã, em que os direitos de grupos subalternizados, entre eles indígenas, foram discutidos e incorporados ao documento -, e do debate, na disciplina da museologia, a respeito das possibilidades políticas e institucionalização das orientações da museologia social - discussão que se inicia com a nova museologia proposta a partir da Declaração de Santiago do Chile (1972).

Retomo, após essa digressão, o subtítulo. Ao inscrever os verbos no gerúndio, evidencia-se o caráter inacabado, mas atento à duração, cuja vibração nos faz (re)viver eventos, torná-los novamente presentes. Entendo esse recurso como uma tática de nos fazer acomodar, de alguma forma, duas questões contidas no projeto das seções - chamadas de partes -, do livro. Primeiro, a narração em tempo presente, em especial das autoras e autores indígenas, nos depoimentos transcritos e apresentados como artigos. Segundo, a inquietação a respeito da validade de temas (que constam nas duas últimas partes) discutidos em 2017, em sua divulgação três anos depois, sem que sejam encarados como superados ou retrospectivos.

Vale atentar para a ideia de tempo ou temporalidade construída no subtítulo e presente nos textos. Estas categorias foram acionadas a partir dos conceitos de memória, memória coletiva, lembrança e experiência comum ou individual. Essas, de igual forma, permanecem/estão em disputa. A memória - enquanto um conceito útil (em especial a partir de Paul Ricoeur, no livro A memória, a história e o esquecimento, publicado pela Editora da Unicamp em 2007) -, ou a lembrança, na forma de um gesto humano de acionar e narrar as experiências, marcaram os textos de autoras e autores indígenas, sendo as teorias propostas por essas(es) pautadas na narração autobiográfica, de um eu composto, ou compósito, constituído intersubjetivamente como um eu-nós. Tal perspectiva, entre outras, permite acessar o que a organizadora denominou indianização do museu. Nesse processo configura-se a autonarrativa indígena como uma tática institucional e crítica para a constituição das ações e políticas de patrimonialização em museus etnográficos e naqueles indígenas. Tais procedimentos promoveriam e assegurariam as demandas não somente por representatividade no amplo espectro do a que se costumou chamar de cultura brasileira, mas, e sobretudo, motivariam deslocamentos de opressões e preconceitos vividos em longa duração e que marcam, ainda hoje, as experiências coletivas dos grupos indígenas nesse território, cuja insistência e cujas disputas violentas definimos como Brasil.

Por outro lado, a palavra, ou o direito e autoridade de falar e ser ouvido, é outra que está em disputa no livro. Ao ter essa questão em quadro, o sumário converte-se em registro, mapa, caminho para entendê-la. Estruturado a partir de consenso institucional e político de que as e os indígenas deveriam 
"falar primeiro" e serem "ouvidos" por leitoras e leitores, no sumário as três primeiras partes foram dedicadas a textos de autoras e autores indígenas e, as duas últimas, a autoras e autores vinculados às instituições museais ou universitárias. Essa apresentação do sumário marca uma postura, de certa forma, militante por parte das associações indígenas, instituições museológicas, universidades e órgãos municipais de cultura envolvidos na constituição dessa relação entre museus etnográficos e indígenas. Assim, o sumário se configura como arena em que as relações de poder entre sujeitos, conhecimento e teorias são deslocadas, rearranjadas e, nesse movimento, promovem debates profícuos sobre os temas propostos para o evento de origem e para o livro que decorre da trilha traçada e percorrida.

Questões como a ética, os direitos indígenas, as formas do sagrado, os acervos e as exposições, a gestão das coleções e, por fim, a relação entre museus, indígenas e museus indígenas são apresentadas de forma tensa, ainda não resolvidas. Como em todo experimento, o livro não tenta dar conta, apaziguar a pluralidade de argumentos e perspectivas. Pelo contrário, procura registrar as questóes formuladas, manter as formas de enunciação - com suas sintaxes e acentos -, verter para a língua portuguesa narrações feitas em idioma Kaingang, Krenak, Terena e Guaraní Nhandewa, apoiar com documentação imagética, notas explicativas, indicação de sítios de internet onde se encontrar informações complementares, como chaves de interpretação das práticas (auto)narradas; este foi o trabalho da organização do volume. Ademais, deixa para as leitoras e leitores o trabalho de articular as teorias formuladas, os argumentos construídos, as ações realizadas, os planos propostos - visto que é necessário trabalhar, trabalhar muito para mostrar com o coração para todo mundo a cultura, como disse um dos autores indígenas.

Entendo, com isso, que a ideia anunciada pela organizadora, retomando o seu texto introdutório, de descolonizar o MIV e o MAE-USP em especial, e a instituição museológica em geral, a partir de sua indianização, estabelece relação, mesmo que marginal, com as propostas de Silvia Rivera Cusicanqui (em seu livro Um mundo ch'ixi desde la história andina, publicado em 2018), da equivalência de capacidades cognitivas entre indígenas e não indígenas no que toca à formulação de teorias sobre o mundo, a vida e a experiência. Decorrem dessa perspectiva da autora o estabelecimento e a validade da diversidade de epistemes no mundo intercultural no qual vivemos, para que possamos constituir outros conhecimentos sobre as realidades sociais interculturais. Refletir sobre as epistemologias não ocidentais e suas relações com aquelas chamadas ocidentais faz parte de um projeto que ultrapassa a reformulação de instituições museais, universidades, estados nacionais. Pressupõe, em primeiro lugar, reconhecer que as instituições ocidentais (não indígenas) foram constituídas e, de alguma forma, refletem a lógica colonial imperialista ocidental. Nesse jogo de lembrar e esquecer, o livro, organizado por Cury, busca a escuta atenta e cuidadosa das e a respeito das narrações, ou melhor, autonarrações das pessoas indígenas, em articulação com os não indígenas. Todavia, isso ocorre não para dar voz àqueles sujeitos, visto que essa empresa é impossível, conforme problematiza Gayatri Chakravorty Spivak, no livro Pode o subalterno falar? (tradução do original realizado pela Editora UFMG, em 2010), mas talvez, para construir um exercício intercultural de alteridade e escuta. 
Certas questões são imprescindíveis de serem pontuadas aqui. Em especial, com relação aos questionamentos que o livro desperta. Dessa forma, tomo a tática de um breve inventário das coisas visíveis, ao modo de Georges Perec no livro Tentativa de esgotamento de um local em Paris (livro-inventário publicado em 2016, pela Gustavo Gili). Algumas dessas indagações foram formuladas no esforço de diálogo intercultural que se deu no EPQIM de 2017. Contudo, acredito que são desdobramentos dos encontros anteriores e das práticas vividas no decorrer dos anos, a saber, visitas técnicas aos museus, formulações de exposições temporárias, crítica e revisão de coleções existentes nas reservas técnicas, debates e rodas de conversa em eventos, oficinas e reuniões, entre outras oportunidades.

A indagação mais deslocadora talvez seja a ideia de museu formulada pelas autoras e autores indígenas. Longe da fixidez dos espaços de pedra e cal, mas não excluindo a materialidade arquitetônica, os museus para essas teorias são ou estão constituídos na experiência - em especial, vinculados àquilo que se quer lembrar ou não esquecer -, os museus seriam entidades discretas, abstratas, situadas e relacionais - todavia, não desprovidas de uma dimensão material, mesmo que discursiva -, onde humanos e não humanos, natureza e cosmologia seriam articulados, podendo ser acionados como uma cosmopolítica. Essa seria preenchida de sentidos e sentimentos, em especial. Já o "lugar" seria formulado tal qual uma categoria intercultural, visto que não há nos grupos indígenas um lugar, na sua estrutura social, para salvaguardar artefatos inúteis. Mesmo a ideia de inutilidade é um tema em aberto, como problematizou Els Lagrou em seu livro A fluidez da Forma: arte, alteridade e agência em uma sociedade amazônica (Kaxinawa, Acre), publicado em 2007.

Decorrente desse aspecto, o que reforça o caráter relacional das questões formuladas por aquelas teorias indígenas, o tempo, ou a temporalidade, é outro tema apresentado. Considerando as práticas indígenas realizadas na forma de relações entre gerações, o tempo passado seria marcado pela presença dos velhos e por práticas verbais e corpóreas, como as conversas, o ensinamento sobre o trabalho, as formas de produção técnica e tecnológicas, entre outras. Em uma perspectiva intercultural o tempo, passado, presente e futuro, passa a ser construído como uma questão a ser problematizada. Logo, a memória - ou aquilo que não se quer esquecer -, passa a ser mais uma categoria intercultural, acionada na materialidade corpórea dos mais velhos, nas suas palavras e histórias - a morte de um velho seria similar ao desaparecimento de uma biblioteca, como comenta uma outra autora indígena. O sentido da memória nessas teorias tem valor prático, à medida que permite aos grupos construírem suas autonarrativas, sustentadas em eventos e em jogos de lembrar e esquecer, caracterizados por Paul Ricoeur no livro citado anteriormente, entre outras coisas, de sua presença no território, de sua ancestralidade e perenidade nos lugares em que se enterraram os antepassados, da existência das fontes onde se retira o material para fazer o artesanato, entre tantas outras práticas que marcam os calendários indígenas.

Ao modo de encerramento desse texto - e na esperança de abertura de um debate profícuo sobre as formas com que procuramos tensamente conviver em sociedades interculturais -, retomo a provocação de García Canclini: faz-se necessário, em contextos interculturais contemporâneos e capitalistas, localizar as resistências aos processos de hibridação. Dito de outra forma, precisamos estar atentos às 
formas com que os grupos subalternizados dão conta das disputas interculturais para, com isso, entender onde suas formas sociais são acionadas como lugares para não esquecer de si.

Ronaldo de Oliveira Corrêa é Doutor em Ciências Humanas pelo Programa de Pós-Graduação Interdisciplinar em Ciências Humanas da Universidade Federal de Santa Catarina (UFSC). Atua como professor na graduação e pósgraduação da Universidade Federal do Paraná (UFPR).

RECEBIDO: $26 / 01 / 2021$

APROVADO: $11 / 03 / 2021$ 